\title{
Desain Aplikasi Sistem Informasi Akuntansi untuk Usaha Bengkel Studi Kasus pada AA Cempaka Auto Service
}

\author{
${ }^{1}$ Jurusan Akuntansi, Politeknik Negeri Padang \\ Email:firm4n2003@gmail.com \\ ${ }^{2}$ Jurusan Akuntasi, Politeknik Negeri Padang \\ Email: elfitrisanti@ymail.com \\ 3 Jurusan Akuntasi, Politeknik Negeri Padang \\ Email: armel yentifa@gmail.com \\ ${ }^{4}$ Jurusan Akuntansi, Politeknik Negeri Padang \\ Email: rinifrima@gmail.com \\ ${ }^{5}$ Jurusan Akuntansi, Politeknik Negeri Padang \\ Email:dedydjefris@gmail.com
}

Firman Surya1, Elfitri Santi², Armel Yentifa ${ }^{3}$, Rini Frima ${ }^{4}$, Dedy Djefris ${ }^{5}$

\begin{abstract}
This study aims to design an accounting information system application in AA Cempaka Auto Service workshop. Case study used as research approach. The application design process begins with studying the forms and reports that are required by the workshop business i.e purchasing form, sales form, general journal form, vehicle service record, debt payment and receivables. Required reports consist of transaction journal records, general ledger, balance sheet, income statement, balance sheet, inventory position, and vehicle service record. Application development stage using Microsoft Access 2007 software and VBA facilities for automation of journal posting and inventory cost calculation based on moving average method. The next step is to test the application to get sufficient confidence in transaction processing by comparing the results of the processing with the manual calculations performed. The implementation process is carried out by converting the initial data on the conversion date and inputting the transaction up to the company's operating date. After carrying out the implementation and conversion, the final stage is to carry out training to users and carry out the process of improvement and adjustments to the application based on feedback received from the user. The system design and implementation process have been deemed successful after the user has stated that the application has met all user needs and is operating properly.
\end{abstract}

Keywords: System, Prototyping, Information, Accounting, Database, Auto Service

\section{ABSTRAK}

Penelitian ini bertujuan untuk mendesain aplikasi sistem informasi akuntansi pada usaha bengkel AA Cempaka. Pendekatan yang dilakukan pada penelitian adalah studi kasus. Proses desain aplikasi dimulai dengan mempelajari formulir dan laporan yang dibutuhakan oleh usahan bengkel berupa formulir transaksi pembelian, penjualan, jurnal umum, servis kendaraan, pembayaran hutang dan penerimaan piutang. Laporan yang dibutuhkan berupa keseluruhan catatan jurnal transaksi, buku besar, neraca saldo, laba rugi, neraca, posisi persediaan dan service record kendaraan. Setelah mempelajari kebutuhan sistem tersebut kemuadia dilanjutkan pada tahap pengembangan aplikasi menggunakan software Microsoft Access 2007 dan fasilitas VBA untuk otomasi posting jurnal dan penghitungan harga pokok persediaan dengan metode rata-rata bergerak. Tahap berikutnya adalah melakukan pengujian aplikasi untuk mendapatkan keyakinan yang memadai atas pemrosesan transaksi dengan membandingkan hasil pemrosesan dengan perhitungan manual yang dilakukan. Proses implementasi dilakukan dengan melakukan konversi data awal pada tanggal konversi dan 
melakukan input transaksi sampai pada tanggal operasi perusahaan. Setelah melakukan implementasi dan konversi, tahap akhir adalah melaksanakan pelatihan kepada pengguna dan melaksanakan proses perbaikan dan penyesuaian terhadap aplikasi berdasarkan umpan balik yang diterima dari pengguna. Proses desain dan implementasi sistem telah dianggap berhasil setelah pengguna menyatakan bahwa aplikasi telah memenuhi seluruh kebutuhan pengguna dan beroprasi dengan baik.

Kata Kunci: Sistem, Prototyping, Informasi, Akuntansi, Database, Bengkel

\section{Pendahuluan}

Perkembangan jumlah kendaraan bermotor terutama mobil penumpang di Indonesia menurut data statistik BPS pada tahun 2017 mencapai angka 15.493 .068 unit. Sejak tahun 2003 sampai 2017 pertambahan jumlah mobil penumpang rata-rata 1 juta unit kendaraan per tahunnya. Kondisi ini merupakan sebuah peluang yang sangat baik untuk usaha bengkel kendaraan. Dengan semakin meningkatnya jumlah kendaraan yang beredar di masyarakat maka kebutuhan akan jasa servis dan perbaikan kendaraan juga akan ikut meningkat. AA Cempaka Auto Service merupakan salah satu usaha bengkel yang terletak di daerah simpang taruko kota Padang. Usaha ini telah berdiri sejak tahun 2012 dan sudah dua kali berpindah tempat usaha. Pemilik usaha ini merupakan seorang mekanik yang telah berpengalaman bekerja pada bengkel servis resmi kendaraan bermotor dengan merk toyota. Keahlian yang dimiliki oleh pemilik usaha yaitu bapak Asrul sudah tidak dapat diragukan lagi. Pengalaman yang didapatkan selama kurang lebih 20 tahun bekerja pada bengkel resmi kiranya sudah lebih dari cukup untuk mulai membuka usaha jasa servis kendaraan sendiri.

\section{Rumusan Masalah}

Berdasarkan observasi dan diskusi yang dilaksanakan pada bengkel AA Cempaka Auto Service dapat didefinisikan permasalahan yang dihadapi oleh pemilik yaitu kurangnya kemampuan untuk mengolah transaksi keuangan dan catatan servis kendaaraan menjadi berbagai informasi yang bermanfaat untuk proses pengambilan keputusan.

\section{Metode}

Metode yang digunakan untuk memberikan solusi atas rumusan permasalahan adalah Software Prototyping (Prototyping). Metode ini dipilih karena penulis sebagai pengembang aplikasi sudah memiliki informasi yang cukup jelas dan memadai terhadap kebutuhan penggunan, rancangan aplikasi yang akan dikembangkan dan waktu yang ditargetkan untuk menyelesaikan aplikasi juga cukup singkat. Menurut definisi dari Wikipedia, "Software prototyping is the activity of creating prototypes of software applications, i.e., incomplete versions of the software program being developed. It is an activity that can occur in software development and is comparable to prototyping as known from other fields, such as mechanical engineering or manufacturing". Metode ini menggunakan 4 langkah untuk mengembangkan sistem yaitu: 1. Identifikasi kebutuhan dasar sistem, 2. Membangun prototipe awal, 3. Review prototipe dan 4. Revisi dan penyempurnaan prototipe menjadi software yang berfungsi sesuai dengan kebutuhan pengguna sistem. 


\section{Identifikasi Kebutuhan Dasar Sistem}

Kebutuhan sistem yang akan dikembangkan untuk usaha bengkel dapat dirinci sebagai berikut: 1. Pengolahan transaksi pembelian, 2. Pengolahan transaksi penjualan dan perhitungan harga pokok, 3. Pengolahan transaksi jurnal umum, 4. Pengolahan transaksi hutang, 5. Pengolahan transaksi piutang, 6. Pengelolaan catatan servis (service record) dan 7. Penyajian laporan keuangan dan pendukung. Seluruh pengolahan dan penyajian laporan dilaksanakan berbasis komputer dengan dukungan DBMS. Aplikasi yang didesain harus mampu berjalan pada platform sistem operasi Microsoft Windows 7 32/64 bit dan dapat dioperasikan secara multi user. Penomoran bukti transaksi dilakukan secara otomatis dengan memanfaatkan fasilitas autonumber.

\section{Membangun Prototipe}

Prototipe aplikasi dikembangkan dengan Microsoft Access 2007. Tahap awal pengembangan dimulai dengan merancang tabel dan relationships antar tabel, kemudian dilanjutkan dengan desain forms dan query yang dibutuhkan untuk input data dan penyajian informasi. Pemrograman aplikasi sebagian besar dilakukan pada tahap pengembangan forms karena forms berkaitan dengan kegiatan input data dan pemrosesan data. Bahasa pemrograman yang digunakan adalah Visual Basic for Application (VBA) yang merupakan bahasa pemrograman yang sudah terpasang pada aplikasi microsoft access 2007. Kode program ditulis untuk berbagai event yang terjadi pada objek forms seperti command button dan event current.Langkah terakhir adalah membuat berbagai laporan yang dibutuhkan sesuai dengan kebutuhan user.

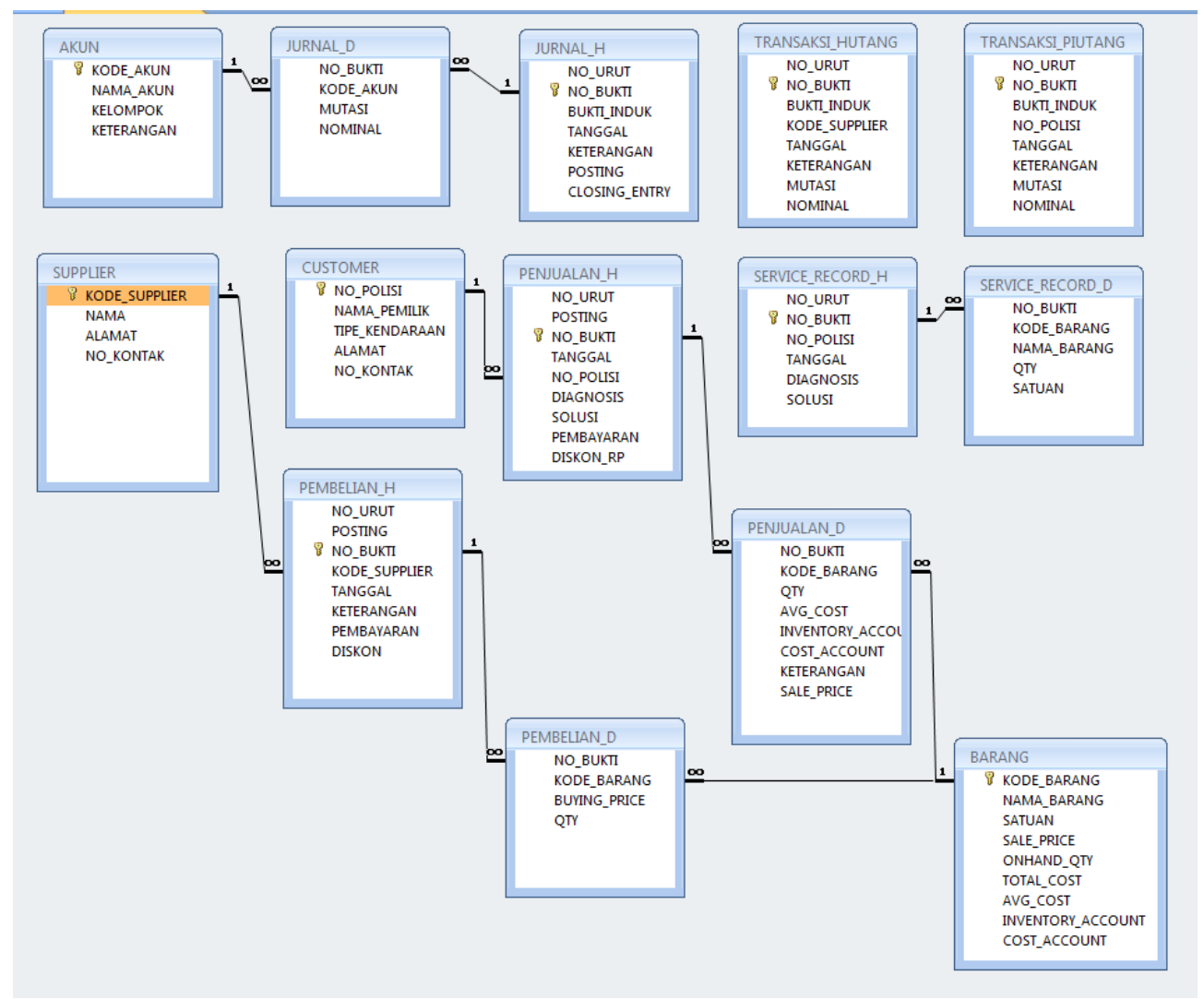

Gambar 1. Relationships antar tabel 


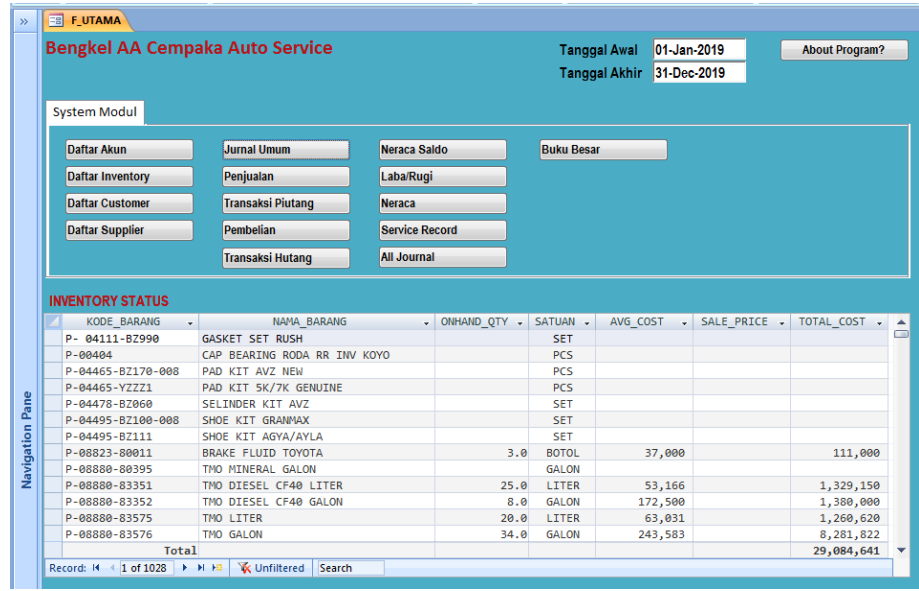

Gambar 2. Menu Utama / Dashboard

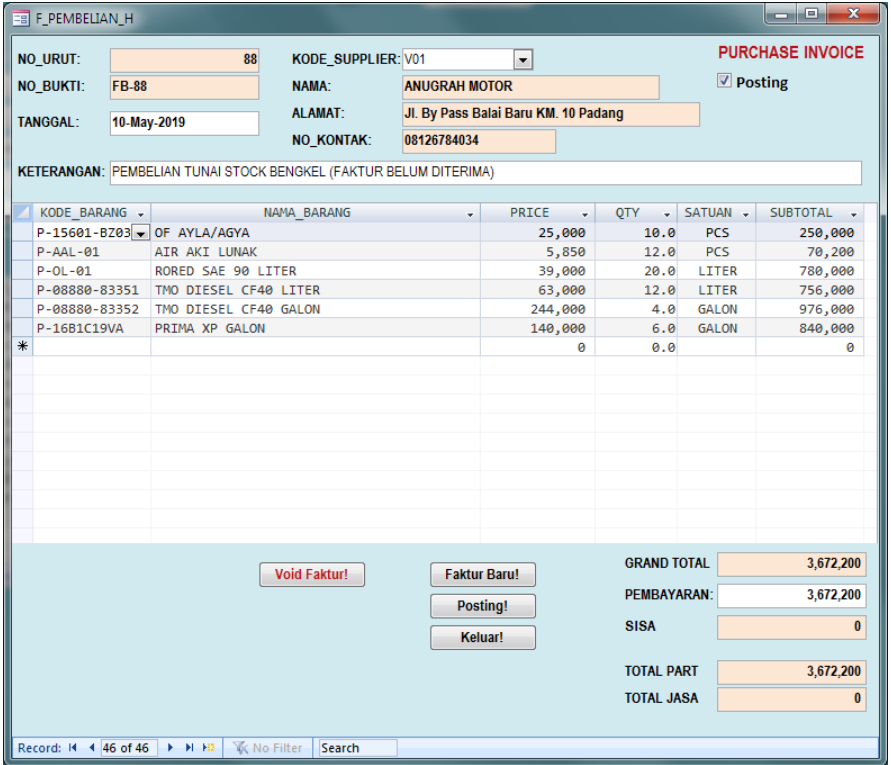

Gambar 3. Pengolahan Transaksi Pembelian

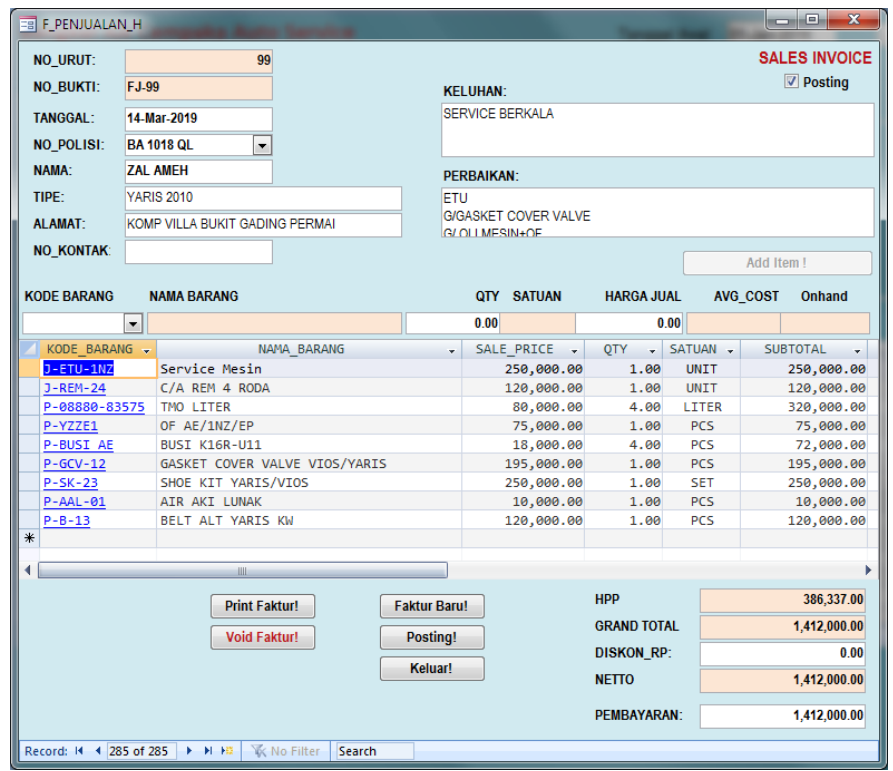

Gambar 4. Pengolahan Transaksi Penjualan 


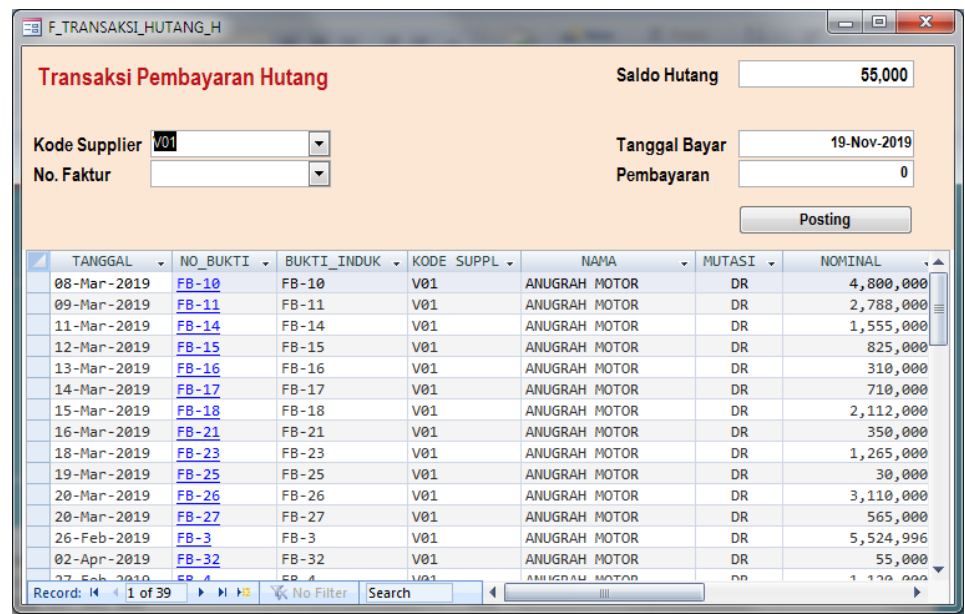

Gambar 5. Pengolahan Transaksi Hutang

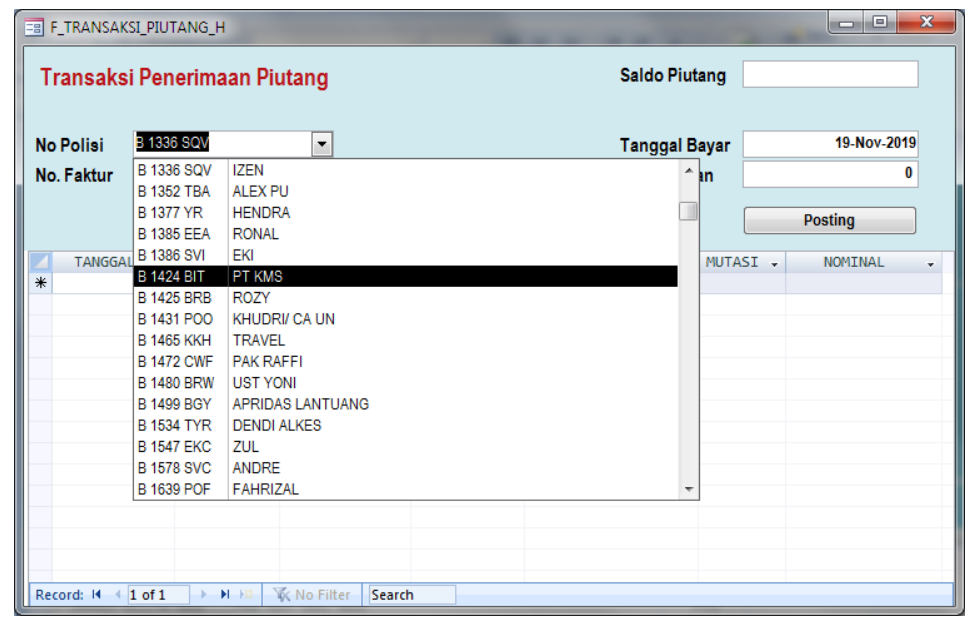

Gambar 6. Pengolahan Transaksi Piutang

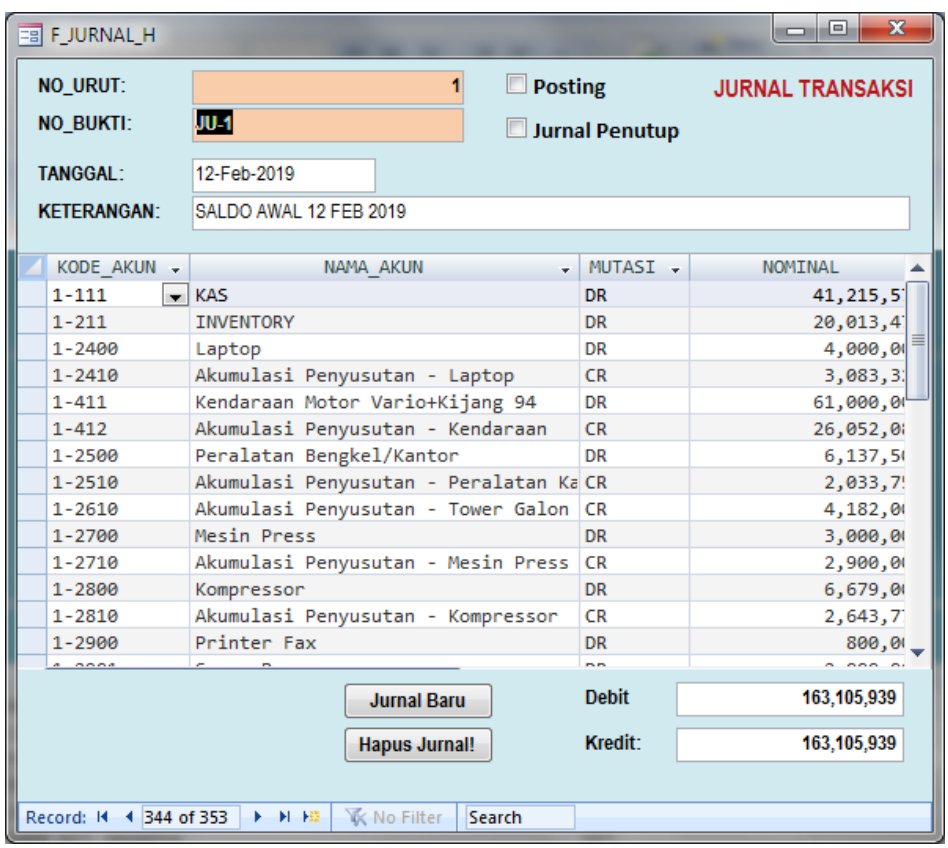

Gambar 7. Pengolahan Transaksi Jurnal Umum 


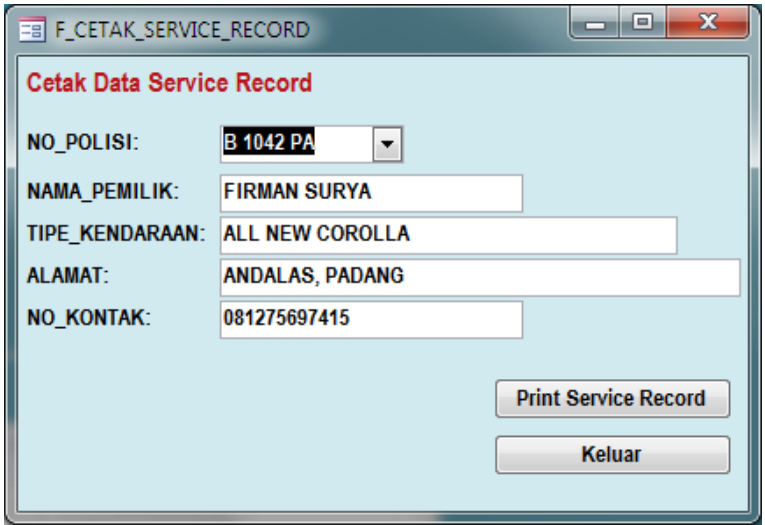

Gambar 8. Inkuiri Data Service Record

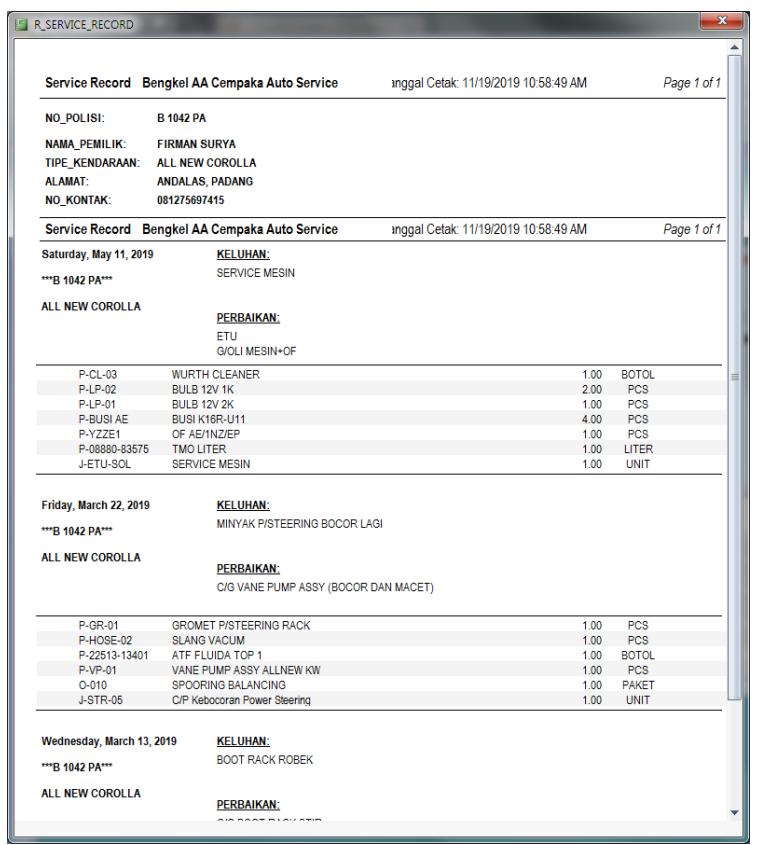

Gambar 9. Laporan Service Record

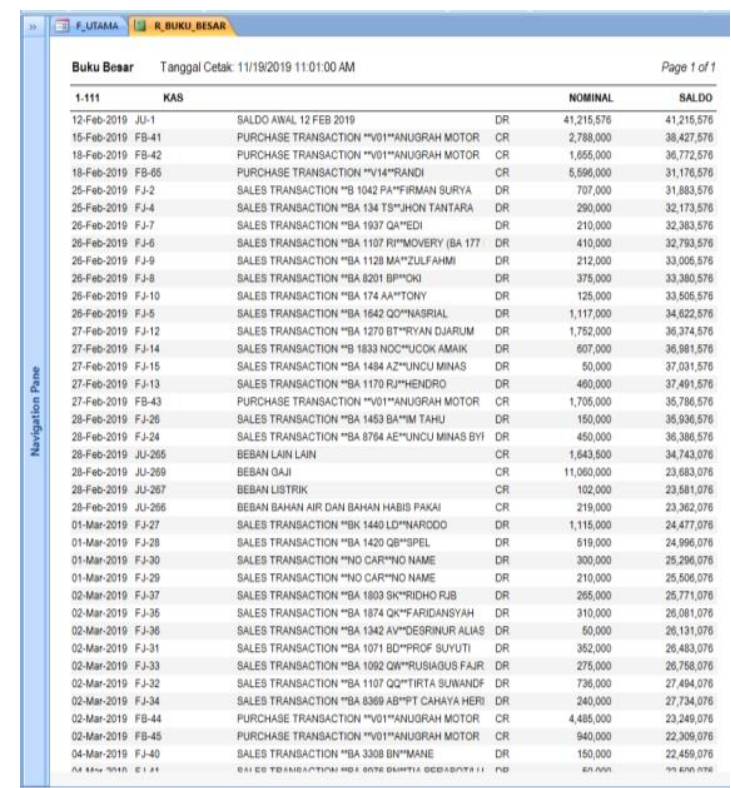

Gambar 10. Laporan Pendukung - Buku Besar 


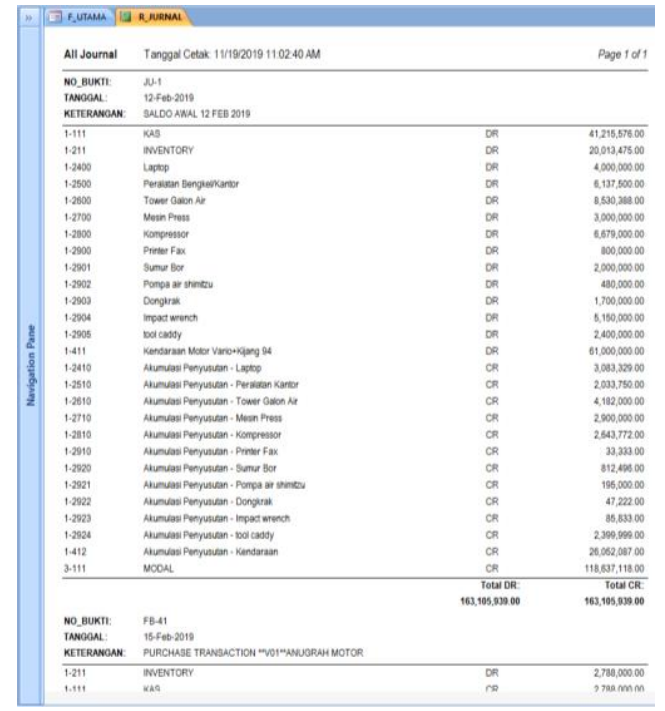

Gambar 11. Laporan Pendukung - All Journal

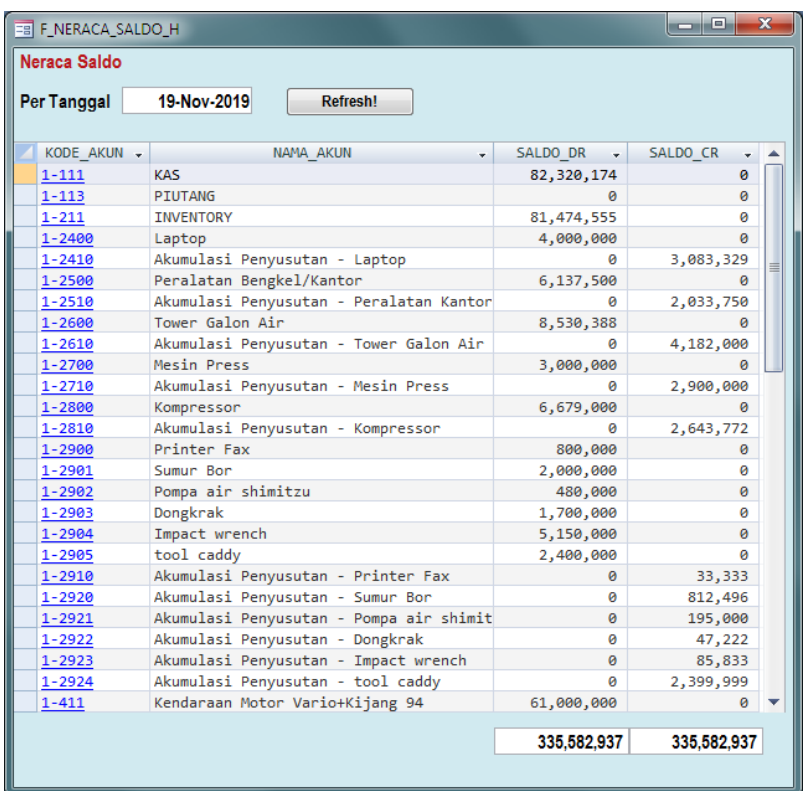

Gambar 12. Informasi Neraca Saldo

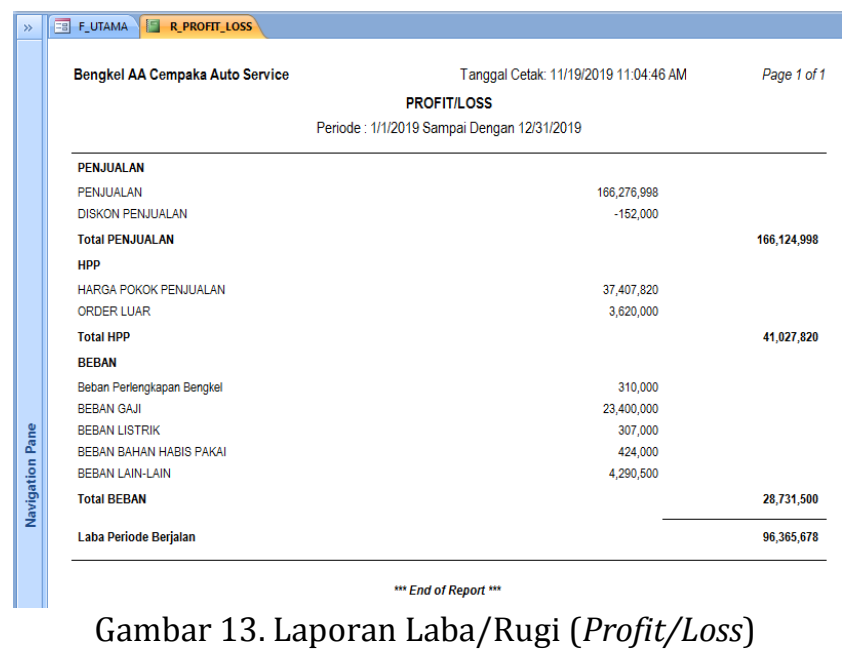




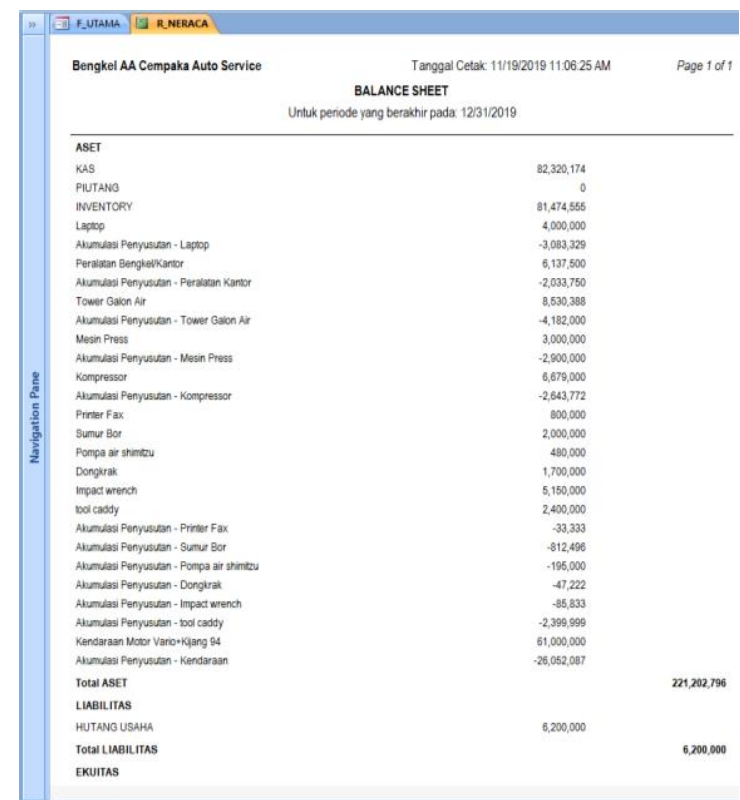

Gambar 14. Laporan Neraca (Balance Sheet)

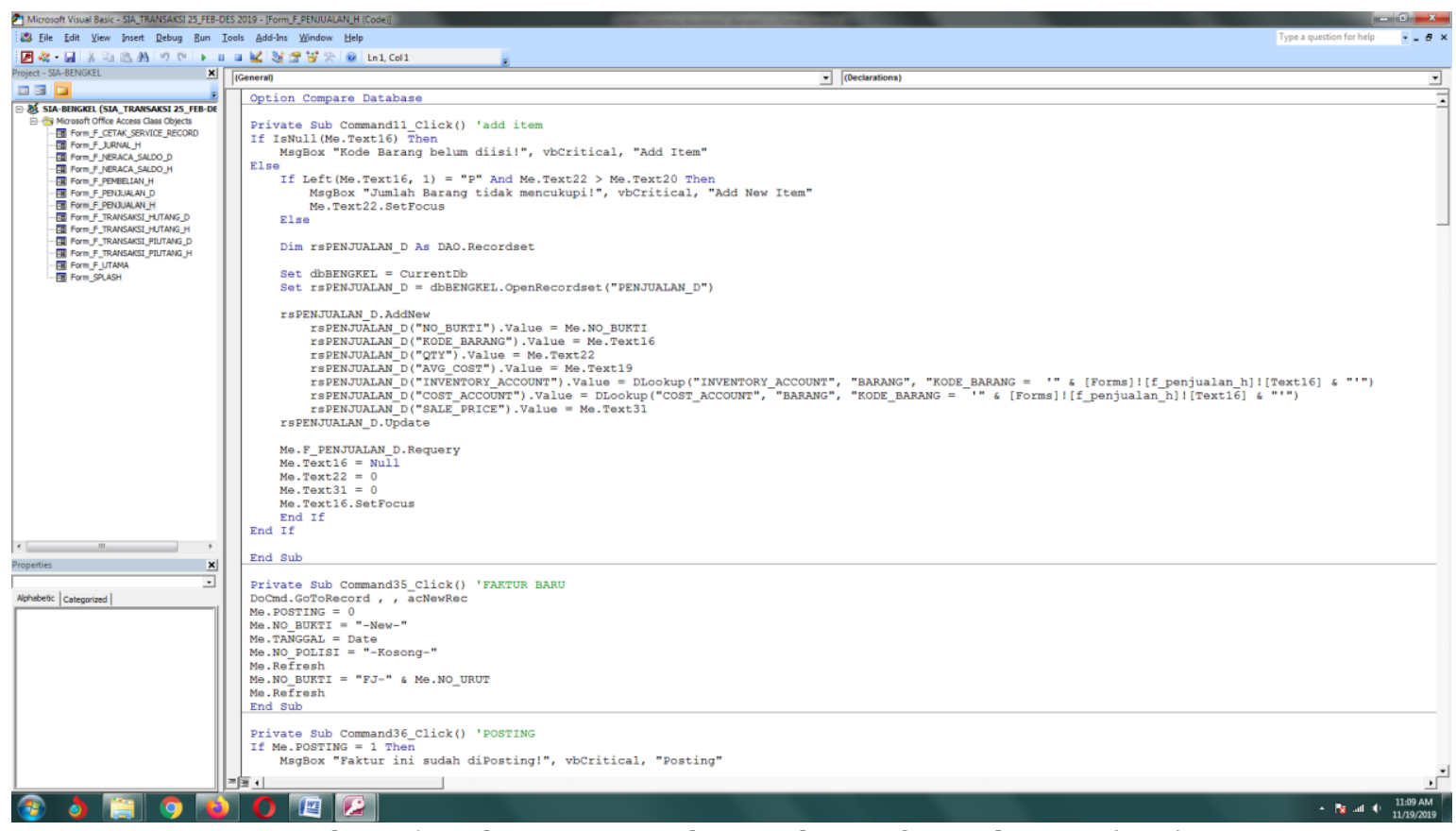

Gambar 15. Kode Program pada Visual Basic for Application (VBA)

\section{Reviu Prototipe}

Setelah prototipe diselesaikan kemudian dilakukan reviu dan uji coba menggunakan data real. Langkah ini ditempuh agar proses migrasi dan koversi data dapat segera dilaksanakan dan mampu memberikan gambaran yang lebih nyata atas kemampuan aplikasi yang dikembangkan saat diberikan data transaksi. Hasil reviu yang dilaksanakan telah memberikan tingkat keyakinan yang memadai untuk menjalankan aplikasi pada basis pengolahan data yang sebenarnya.

\section{Revisi dan Penyempurnaan}

Berdasarkan hasil reviu yang telah dilaksanakan sebelumnya dan proses penggunaan aplikasi yang telah berjalan sekitar 2 bulan didapatkan keluhan dari pengguna untuk 
memperbaiki beberapa fungsi yang tidak berjalan sesuai dengan harapan diantaranya adalah kebutuhan pengguna agar data transaksi pada forms dapat ditampilkan secara urut sesuai dengan penomoran pada autonumber bukan sesuai dengan tampilan saat ini yang urut berdasarkan nomor bukti transaksi. Selain itu juga diatasi beberapa kendala teknis yang tidak begitu berarti.

\section{Kesimpulan}

Kebutuhan aplikasi pengolahan transaksi keuangan dan pencatatan servis (service record) telah berhasil dikembangkan menggunakan microsoft access 2007 dengan metode prototyping dan berjalan dengan baik. Alasan pemilihan metode prototyping karena kebutuhan dasar aplikasi sudah diidentifikasi dengan baik dan proses pengembangan aplikasi dapat dilaksanakan dalam waktu yang singkat.

\section{Referensi}

[1] bps.go.id, Perkembangan Jumlah Kendaraan Bermotor Menurut Jenis 1949-2017, $\begin{array}{lllll}\text { diakses } & \text { pada } & 19 & \text { November }\end{array}$ https://www.bps.go.id/linkTableDinamis/view/id/1133

[2] Wikipedia.org, Software Prototyping, diakses pada 19 November 2019, dari https://en.wikipedia.org/wiki/Software prototyping 